\title{
EXÍLIO E HISTÓRIA: UMA PERSPECTIVA DO OFÍCIO DO HISTORIADOR A PARTIR DO ATLÂNTICO NEGRO
}

M. V. L. QUEIROZ
$\begin{gathered}\text { Faculdade de Direito, Universidade de Brasília } \\ \text { marcosvlq@gmail.com }\end{gathered}$
Submetido $21 / 07 / 2016$ - Aceito $13 / 01 / 2018$
DOI: $10.15628 /$ holos.2018.4866

\section{RESUMO}

O artigo pretende examinar a figura do "exilado" e suas respectivas contribuições para o ofício de historiador no regime de historicidade da modernidade. Para tanto, primeiramente e a partir das abordagens de Charles Baudelaire e da Paris do século XIX feitas por Walter Benjamin, serão analisadas as qualidades desse tempo histórico e os desafios que ele traz para a historiografia. Em um segundo momento, recuará e perceberá a categoria do "exílio" como inerente aos processos políticos e culturais do Atlântico Negro, bem como às perspectivas e às narrativas distintivas produzidas pela diáspora negra em seu trânsito pela modernidadecolonialidade. Espera-se, assim, que a exploração da ideia de "exílio", ancorada nas experiências de negros e negras no mundo atlântico, forneça um arcabouço instrumental para se pensar a história e o historiador na contemporaneidade.

PALAVRAS-CHAVE: história, exílio, Atlântico Negro, modernidade, colonialidade

\section{EXILE AND HISTORY: A PERSPECTIVE OF THE HISTORIAN'S CRAFT FROM THE BLACK ATLANTIC}

\begin{abstract}
The paper intends to examine the figure of "exile" and its contributions to the historian's craft in the modern regime of historicity. Firstly, from Walter Benjamin's approaches of Charles Baudelaire and Paris in the 19th century, it analyzes the qualities and the challenges of this historic time to the historiography. In a second time, the paper works the category of "exile" as inherent to
\end{abstract}

the political and cultural processes of the Black Atlantic, as well as to the distinctive narratives produced by the African Diaspora in the modernity-coloniality. Thereby, it is expected that the idea of "exile", anchored in the experience of people of African descent throughout the Atlantic world, provides an instrumental framework to think the history and the historian in contemporary.

KEYWORDS: history, exile, Black Atlantic, modernity, coloniality 


\section{INTRODUÇÃO}

[...] a vida moderna começa com a escravidão... Do ponto de vista das mulheres, em termos de enfrentar os problemas que o mundo enfrenta agora, as mulheres negras tiveram de lidar com problemas pós-modernos no século XIX e antes. Essas coisas tiveram de ser abordadas pelo povo negro muito tempo antes: certos tipos de dissolução, a perda e a necessidade de construir certos tipos de estabilidade. Certos tipos de loucura, enlouquecer deliberadamente, como diz um dos personagens no livro, "para não perder a cabeça". Essas estratégias de sobrevivência constituíam a pessoa verdadeiramente moderna. São uma resposta a fenômenos ocidentais predatórios. Você pode chamar isto de ideologia e de economia, mas trata-se de uma patologia. A escravidão dividiu o mundo ao meio, ela dividiu em todos os sentidos. Ela dividiu a Europa. Ela fez deles alguma outra coisa, ela fez deles senhores de escravos, ela os enlouqueceu. Não se pode fazer isso durante centenas de anos sem que isso cobre algum tributo. Eles tiveram de desumanizar, não só os escravos, mas a si mesmos. Eles tiveram de reconstruir tudo a fim de fazer este sistema parecer verdadeiro. Isto tornou tudo possível na Segunda Guerra Mundial. Tornou necessária a Primeira Guerra Mundial. Racismo é a palavra que empregamos para abarcar tudo isso (Morrison, 2000, apud Gilroy, 2012, p. 412-413).

Não é de bom tom começar um trabalho acadêmico com uma citação, sobretudo quando ela é longa. No entanto, as palavras da escritora estadunidense Toni Morrison primam, paradoxalmente, pela síntese ao trazer, precisamente, uma série de temas que são vastamente ignorados pela narrativas hegemônicas ocidentais, entre elas as da ciência da história e a da filosofia. Ou melhor: temáticas que são abordados por esses discursos, mas de uma maneira específica que as restringe a um contexto determinado, a Europa a partir do final do século XVIII, apagando a presença da diáspora negra naquilo que se convencionou chamar de modernidade.

A abordagem de Morrison realiza uma aproximação com temas que são sensíveis à historiografia, à reflexão filosófica e à própria consciência social desenvolvidas no século XX, sobretudo diante dos contextos pós-traumáticos das duas guerras mundiais (Koselleck, 2014), os quais ensejaram novas abordagens da temporalidade do tempo presente. Em uma articulação premonitória, a capacidade singular de Benjamin (1987), ao abordar o desaparecimento da figura do narrador, expõe características singulares desse período, em que a destruição da experiência, advindos do trauma e de uma violência indizível, bem como o excesso de informação (iniciado com o boom da imprensa no século XIX), tornaram impossível o ato de narrar. Assim, uma rasura foi estabelecida sobre o ato comunicacional de transmissão da conhecimento vivido, da própria experiência.

No que pode ser entendido como uma radicalização do regime de historicidade moderno ${ }^{1}$, concebidos por outros como a própria inauguração de uma nova temporalidade (Hartog, 2015), as formas de articular passado, presente e futuro mudaram radicalmente. Se no início da modernidade, na esteira do iluminismo e da Revolução Francesa, é gestada uma nova forma de perceber e se fazer a história (Koselleck, 2006), em que ela deixa de ser um mero repositório de experiências e passa a poder ser feita no próprio presente, articulando uma

\footnotetext{
${ }^{1} \mathrm{O}$ conceito de "regime de historicidade" é retirado da obra de François Hartog, que, resumidamente, significa uma maneira de engrenar ou de compor passado, presente e futuro tendo em vista a constituição de uma categoria comparativa que pode tornar mais inteligíveis as diversas experiências do tempo (HARTOG, 2015).
} 
concepção do futuro enquanto progresso da racionalidade e da agência humana, os acontecimentos históricos do século XX trazem uma crise para essa percepção temporal.

O totalitarismo, o genocídio, a utilização da ciência para os mais extremos absurdos e outras experiências do indizível levam à crise do regime de historicidade moderno, ou, na percepção antecipatória de Benjamin (1989) e na concepção de Gumbrecht (2015), a uma radicalização da temporalidade moderna. O futuro, como uma melhora em relação ao presente ou um leque de possibilidade aberto, se torna cada vez mais incerto e ameaçador. O passado não é mais um tempo a ser superado, algo que se foi, transformando-se em uma "presença", um "real" emanador de sentidos que transborda sobre o presente (Certeau, 2011). O presente é ampliado, dilatado e estendido, alargando-se e perdendo suas delimitações em relação ao passado e ao futuro (Hartog, 2015; Gumbrecht, 2015). Nesta nova temporalidade, o passado emerge como uma demanda e o futuro não é mais uma possibilidade em aberto.

Voltando a Morrison, a rasura, colocada por uma percepção da história que enxergue a humanidade para além da Europa e compreenda o colonialismo como fenômeno inerente à modernidade (Bernardino-Costa, 2015), faz necessária uma reperiodização (Hall, 2013) que seja capaz de antecipar e deslocar os dilemas e questões do mundo moderno para além das fronteiras dos estados-nação europeus. Neste sentido, o complexo colonial e a escravidão emergem como marcos constitutivos das vidas negras na diáspora africana (Fanon, 2008), em que a noção e a experiência do "exílio" fornecem uma perspectiva singular dos fenômenos que afligem a contemporaneidade (Gilroy, 2012).

Diante dessas considerações, o presente artigo pretende, a partir das discussões estabelecidas por Benjamin em torno de Baudelaire e da Paris do século XIX, perceber como a figura do exilado, do estrangeiro ou daquele que é estranho a um determinado meio, possui relevância para se pensar características particulares do ofício do historiador no regime de historicidade da modernidade. A partir dessas considerações, analisar-se-á como a condição de exílio não foi somente uma imposição do colonialismo sobre negros e negras na diáspora, servindo também como ponto de articulação intelectual, ética e teórica para se reconstruir o passado, borrando as narrativas hegemônicas centradas na ideia de nação, e projetar um futuro mais justo e democrático.

\section{MODERNIDADE E EXÍLIO: A PERSPECTIVA DO ESTRANHO DO SEU PRÓPRIO TEMPO}

Recortado na sua própria carne pelos eventos do início do século XX, o filósofo alemão Walter Benjamin é um dos pensadores centrais para captar o conjunto de transformações engendradas pela modernidade na medida em que, já na década de 1920, antecipa toda uma problemática inerente à reflexão filosófica dos séculos XX e XXI. Ao refletir sobre a destruição da experiência advinda do trauma (a violência indizível dos regimes totalitários) e do excesso de informação (oriundo da expansão da imprensa, que substitui o ato de narrar pela simples reprodução dos fatos), Benjamin intenta descrever a vivência tipicamente moderna decorrente da hiperaceleração do tempo, bem como busca enfrentar a pergunta: como é possível construir narrativas coerentes perante uma realidade que se modifica a todos instante?

Em seu texto "O Narrador: considerações sobre a obra de Nikolai Leskov", escrito em 1936, é possível perceber como a erosão do mundo artesanal - lento, parcimonioso e atrelado à reprodução das práticas tradicionais - e a emergência da vida urbana moderna deslocam e 
impossibilitam o próprio ato de narrar: os sujeitos, com o decorrer da modernidade, deixam de ter experiência, transmitidas por narrativas (um discurso que se repete prolongadamente através do tempo), para ter traumas circulados através de informação (discursos plausíveis, pontuais e hipercontextualizados, de próxima distância e fugazes) (Benjamin, 1987).

Neste sentido, nada mais fascinante para se pensar o regime de historicidade moderno e suas relações com a história do que a descrição da Paris do século XIX elaborada por Benjamin a partir da figura do poeta boêmio Charles Baudelaire (1989). É nesta cidade, sobretudo a partir da segunda metade do século XIX, que Benjamin perceberá a forma originária da modernidade, vendo na vida urbana parisiense o modelo embrionário da sociedade de massas e do totalitarismo (Machado, 2006).

Esta Paris expressa, na sua própria superfície, o ímpeto destruidor do tempo da modernidade, no qual tudo - inclusive as mais recentes novidades - é transformado em entulho e passado. Uma cidade que é um campo de obras e de ruínas, em que a presença de monumentos e edifícios divide a paisagem com instrumentos e instalações de reforma urbanística. Nela, imagens que são imediatamente feitas a partir da vida logo dão a impressão de experiência já passada, já extinta ou prestes a morrer. É uma cidade com seu próprio regime de historicidade: nela, o presente é a todo momento produzido, antecipando nele próprio um futuro incerto e desolador; no entanto, é também um presente que, na mesma rapidez e fugacidade, torna-se obsoleto. Uma cidade que é produção e criação permanente de ruínas, entulhos e dejetos (Benjamin, 1989).

Como Benjamin aponta, Baudelaire, no poema "O Cisne", capta este momento parisiense. É uma cidade quebradiça e transparente como o vidro - mudando mais rápido que o coração infiel. A fragilidade é preenchida pela desolação do que se foi e a desesperança pelo que virá. Na debilidade, a modernidade se alia à antiguidade. E nesta cidade há a tentativa de aniquilar o espontâneo, que possibilita o encontro com a palavra do poeta, e de limpar completamente o entulho por meio da limpeza, apagando, assim, a presença do passado (Benjamin, 1989).

E se no relevo parisiense do século XIX é possível identificar um estatuto específico do tempo, aquele que será generalizado e aprofundado com o avançar da modernidade, nesta mesma Paris baudelairiana podemos encontrar figuras que desempenham, nas suas relações com a cidade, funções que trazem questões interessantes para se pensar o ofício do historiador neste novo regime de historicidade. Uma delas é o trapeiro, aquele que recolhe na capital o lixo do dia que passou, ou seja, tudo aquilo que na cidade grande se perdeu, foi desprezado, destruído ou jogado fora. Todas essas coisas são reunidas e registradas por ele. $\mathrm{O}$ trapeiro separa e faz uma seleção inteligente, dotando de utilidade e agradabilidade o entulho produzido pela sociedade (Benjamin, 1989).

Portanto, como o historiador, o trapeiro alia a função arquivista típica do antiquário, aquele que coleta referências e fontes soltas que já são tidas como lixo (Ginzburg, 1993), com a função articulatória de dar sentido ao que a "marcha da civilização" jogou fora ou relegou ao passado.

Da mesma maneira que pertence aos trapeiros, a escória também é íntima dos poetas, outra figura interessante da Paris baudelairiana para se pensar a história. Assim como os que saem para catar lixo à noite, os poetas realizam seus negócios nas horas em que os burgueses se entregam ao sono, quando a penumbra dos tempos se lança sobre o presente produzindo o 
passado. Eles caminham pela cidade para catar e fazer rimas na busca de cristalizar, em versos, os momentos das relações instáveis e entrecortantes da cidade grande. Sujeitos que se entregam às ruas como um local de refúgio, mesmo sabendo da fragilidade dessa existência. Eram aqueles que transformavam a necessidade em virtude. Sendo também um flâneur, contemplavam e imergiam no meio da multidão, mas conservavam sua estranheza e individualidade, sem desaparecer nas massas e sem se esquecer de si mesmos (Benjamin, 1989).

Essas duas figuras, encarnadas nas diversas facetas de Baudelaire, dão importantes pistas para se pensar o ofício do historiador no regime de historicidade da modernidade, no qual a construção dos liames linguísticos entre o presente e o passado ocorre em um tempo de incertezas e instabilidades - o passado se tornou turvo, ainda que transbordando e tendo consequências no presente, e o futuro deixou de ser visto através das lentes do progresso e da certeza, tornando-se ameaçador e obscuro. E nesta temporalidade parisiense, talvez seja o próprio Baudelaire a peça central para o fazer da história e para avançarmos nas aproximações entre exílio e historiografia.

Baudelaire era um contemporâneo no sentido proposto por Agamben (2009), ou seja, aquele que é estranho e estranha o seu próprio tempo. Os papéis da sua época estavam indisponíveis para sua personalidade, assim como sua ausência de convicção o impedia de refugiar-se na devoção. Estava sempre a assumir novos personagens: o flâneur, o apache, o dândi, o trapeiro, o poeta e etc. Era aquele que circulava por aí assumindo diferentes figuras, percebendo diferentes pontos de vista, mas que também estranhava o seu próprio presente e o mundo que o circundava (Benjamin, 1989). Baudelaire era, assim, um exilado no seu próprio tempo, um estranho à sua própria contemporaneidade, um estrangeiro ao seu próprio habitat.

Além disso, Baudelaire era um incógnito, alguém que conspira com a própria língua, não preso a papéis, instituições e partidos, sendo um provocador e indolente (Benjamin, 1989). Ao encarar a morte e o suicídio e tendo dimensão da precariedade da vida na modernidade, ele tinha, como o apache, certo desprezo pelas virtudes e pelas leis sociais, percebendo o contrato social como aquilo que ele eminentemente é: uma construção humana.

Como um experimentador de todas as sensações e impulsos da Paris do século XIX, Baudelaire movimentou-se e vivenciou situações diversas, deslocando sua perspectiva constantemente. Realizou, assim, um movimento de se despojar, de ir em direção ao desconhecido e ao outro e com ele estabelecer uma linha de comunicação, no sentido que Prost toma como essencial para o bom ofício do historiador (2008). Além disso, sendo indolente, provocava o dissenso, falava ao poder e o desnudava como precariamente humano. Mas mais do que isso, ao centrar nas figuras ignoradas e tidas como vis da sociedade parisiense, tornava presente o ausente, considerava o estado de emergência que ameaçava de extinção os excluídos pela modernidade impetuosa da nova Paris (Benjamin, 1989; Said, 2005).

Assim, na figura de Baudelaire, a partir de todas essas articulações, é possível visualizar aquele que é "estrangeiro de si mesmo" (Kristeva, 1994) - exilado da sua própria contemporaneidade. Ao não tomar nada como certo e natural, justamente por não ser um "nativo", realiza perguntas ingênuas e de superfície; perguntas sobre aquilo que a sociedade jogou fora. Para ele, todo particular é útil para a compreensão da realidade. Busca, assim, enxergar a penumbra existente no presente, a qual deve ser percebida diante das luzes ofuscantes do mundo contemporâneo (Agamben, 2009). 
Além disso, possui uma carga de ingenuidade e de estranhamento perante tudo que é naturalizado, pois sabe que ali reside a verdade do poder (Said, 2005). Em sua perplexidade perante o presente e o passado, desloca os sensos comuns da sua época e irrompe contra a "corrente contínua do rio". Esse modo de pensar no exílio é constantemente e necessariamente uma crise de identidade, um não-lugar oriundo dessa extraterritorialidade.

$\mathrm{Na}$ articulação precisa de Said sobre o intelectual, este, assim como o exilado, nunca se considera nativo dos novos locais que ocupa (até por que nunca é visto como tal), estando sempre em um estilo de vida excêntrico e não-convencional. É esse estilo que lhe permite, como em Baudelaire e suas diversas figuras, um ponto de vista privilegiado e crítico de percepção, desnaturalizando os fenômenos sociais e desnudando o poder como algo humildemente humano (Said, 2005). Ao irromper contra a marcha da história dos vencedores e fornecer uma narrativa contra-hegemônica, desobscurecendo o outro, profana o dispositivo ao deixar de vê-lo como divino (Agamben, 2009).

Em texto sobre o teórico alemão Siegfried Kracauer², Ginzburg (2007) estabelece diretamente as relações entre o historiador e o exilado. Este último é o sujeito que tem uma experiência fragmentada, que necessariamente adquire a subjetivação do não-pertencimento. Da mesma forma, a viagem do historiador é um exílio no tempo, bem como um exílio para fora de si mesmo. Fazer história é sair do próprio "eu" e entregar-se ao outro indeterminado. Em Kracauer, a própria experiência de exilado possibilitou a ele não só o fazer da história, mas também a capacidade de pensá-la epistemologicamente e metodologicamente. Portanto, fez das dificuldades da extraterritorialidade um valor positivo.

$\mathrm{Na}$ introdução da obra "History, the last things before the last", do próprio Kracauer (1995), o filósofo Paul Oskar Kristeller chama a atenção para como a condição de exílio e de extraterritorialidade de Kracauer se aliaram a uma vida excêntrica e desamarrada de dogmas, correntes e instituições acadêmicas, conduzindo-o a um certo pessimismo ativo bastante criativo. É devido a essa postura, decorrente da descrença em alcançar qualquer essência ("as últimas coisas"), que Kracauer se atraia mais pelas "últimas coisas antes da última". A história o atraia pelo seu caráter provisional, pelo seu desejo de dar significado a áreas que reclamam ser reconhecidas na sua própria particularidade. Neste sentido, o fazer historiográfico devia lidar com a capacidade de reabilitar objetivos e modos de ser os quais possuem um vazio conceitual ou então que foram obscurecidos ou mal interpretados (1995).

Portanto, era sua condição de exílio e de estranheza que o convidava não a encontrar uma origem última, mas sim o frescor dos inícios, quando o jogo ainda era jogado e quando as formas históricas ainda não estavam definidas; quando as marcas de verdade ainda não haviam sido estabilizadas. É neste movimento que se procura trazer de volta para a história a própria história, na concepção de Rancière (2011), pois busca-se enxergar no passado o imprevisível, o diferente e o disruptivo, aquilo que desestabiliza e rasura uma determinada temporalidade que hoje chega até nós como eterna. Perceber a singularidade e a particularidade no que passou é fazer emergir a condição de exilado, de estrangeiro ou de extraterritorialidade nos eventos

\footnotetext{
${ }^{2}$ É interessante notar que Kracauer, assim como Benjamin, foram não só dois intelectuais que se viram exilados em decorrência do nazismo na Alemanha (o segundo tendo um destino mais trágico e precoce que o primeiro). Ambos também foram importantes pensadores do regime de historicidade da modernidade, tendo como ponto de partida as reflexões sobre a Paris do século XIX. Além de tudo, foram amigos (Machado, 2006).
} 
históricos, ou seja, no sentido oposto de semelhança total com o seu próprio tempo. É a atitude de tornar visível o movimento da diferença no passado e de profanar aquilo que se apresenta narrativamente como homogêneo.

Assim, a experiência do exílio, no seu deslocamento doloroso e forçado, traz consigo a impossibilidade de um passado como ele exatamente foi. Ademais, a situação de exílio a todo momento é atravessada por um passado que transborda, fisicamente e subjetivamente, na experiência do presente. Mas mais do que tudo isso: o exilado possui um ponto de vista privilegiado a partir da sua própria hermenêutica, pois, ao ser um estranho à sua própria contemporaneidade, extrai dessa condição um ponto de vista distintivo que facilita a percepção da diferença, do deslocado, do ocultado e do imprevisível em um passado que muitas vezes se coloca como homogêneo. Do seu borrão temporal contemporâneo, do seu não-lugar no presente, o exilado desconfia de qualquer totalidade que se coloca como ponto de mediação absoluta para compreender o passado. A sua marginalidade depõe contra as grandes narrativas hegemônicas, as "histórias dos vencedores".

Em um mundo tomado pelo impedimento do ato de transmitir a experiência por meio da figura do narrador e consciente da impossibilidade de acessar o passado tal como ele foi, o exilado aproxima-se da história por meio da dor, da poética, da estética e da afinidade subjetiva. São essas novas manipulações linguísticas que emergem, no século XX, justamente para lidar com um tempo acelerado e incerto, que não só desfigurou o lento e parcimonioso mundo artesanal, mas que também vê descreditadas as estruturas totalizantes de produção de narrativa. Em um afã de democratizar a história e fazer justiça no presente, pluralidade de vozes e de métodos emergiram para lidar com um passado violento e inefável. De alguma maneira, são vozes e métodos dos exilados contemporâneos no regime de historicidade quebradiço da modernidade.

O que se pretende agora é perceber que a condição do exílio não é uma particularidade das realidades pós-traumáticas dos séculos XIX e XX, mas sim uma situação que emerge nos primórdios da modernidade e do seu lado obscuro, o colonialismo. A partir da realidade geopolítica do Atlântico Negro, notar-se-á como essa condição é parte constitutiva da experiência da diáspora africana, fornecendo uma contracultura à modernidade que tem como elemento fundamental a articulação de uma perspectiva distintiva para acessar e narrar o passado.

\section{A DIÁSPORA COMO HISTÓRIA: A PERSPECTIVA DO EXILADO NAS NARRATIVAS DO ATLÂNTICO NEGRO}

Publicado em 1993, o livro do sociólogo e filósofo britânico Paul Gilroy foi o responsável por implantar e popularizar o termo "Atlântico Negro", o qual já tinha sido utilizado anteriormente pelo historiador Robert Farris Thompson, para descrever o espaço geográfico e cultural que emergiu da experiência em massa de deslocamento oriundo da diáspora africana (Dubois e Scott, 2010). Como escreve o próprio Paul Gilroy, o livro surgiu enquanto ministrava aulas de história da sociologia para estudantes que não tinham tanto interesse na matéria. Ao procurar convencê-los sobre a importância de compreender e discutir a história e a herança do iluminismo, ele empenhou-se em demonstrar, pontuar e dimensionar o fluxo do material centrado na Europa com "observações extraídas das contribuições discordantes de autores negros sobre os interesses iluministas e contra-iluministas". Ou seja, o "Atlântico Negro", como 
categoria analítica, desenvolveu-se a partir das tentativas de mostrar que as experiências do povo negro faziam parte da modernidade, ainda que as narrativas hegemônicas apagassem ou obliterassem esse processo. Ademais, o termo buscava provar e significar os discursos produzidos pelos intelectuais negros e negras a respeito do sentido de sua inserção no mundo moderno, "às vezes como defensores do Ocidente, outras vezes como seus críticos mais agressivos" (Gilroy, 2012, p. 27).

Portanto, para Gilroy, o "Atlântico Negro" é uma unidade de análise única e complexa do mundo moderno a partir de uma perspectiva transnacional e intercultural. Ela busca superar a imagem consolidada, nas visões sobre a história da escravidão no mundo atlântico, na qual os negros e negras escravizados eram percebidos como objetos ou seres passivos - e, portanto, objetos passivos da história, incapazes de articular resistências, projetos políticos, revoltas, discursos e lutas de liberdade contra o sistema que os objetificava e explorava (Queiroz, 2017). ${ }^{3}$

Neste contexto, a experiência de vida de negros e negras da diáspora africana no Atlântico Negro começa com o encontro colonial, em que a estrutura colonizadora europeia instaurou uma nova ordem à força, conformando padrões sociais nas sociedades ditas periféricas (Connell, 2012). De impacto, extensão e escala singular, a violência colonial procurou abolir, de um dia para o outro, as metafísicas, costumes e instâncias de referência das populações colonizadas, pois estavam em contradição com uma civilização que não conheciam e que lhes foi imposta. O "ser" desses povos passou a ser constituído violentamente a partir de uma zona do não-ser, em que o mundo ocidental, branco e europeu lhes obrigou a se situar perante dois sistemas de referência (Fanon, 2008).

É desse encontro e de suas respectivas consequências que serão extraídas todas as singularidades da política cultural negra na modernidade. A violência colonial implicou em um processo forçado de desterritorialização, em que populações inteiras foram transportadas e fragmentadas por diversas partes do globo, tendo que, nestas novas realidades, recriar novos modos de vida em contextos que além de não lhes ser próprio, era-lhes hostil (Mintz e Price, 2003). Perante a realidade violenta da escravidão e a precariedade de vida no pós-abolição, os descendentes da diáspora africana encontraram neste "novo mundo" uma série de dificuldades que dificultaram a transmissão geracional e intergeracional da experiência e a formação de uma "esfera pública" própria capaz de impulsionar uma formação política independente.

Neste cenário, o exílio aparece não só como uma metáfora ou uma singularidade de poucos indivíduos, mas sim como marca distintiva das formações culturais e políticas negras na modernidade. Desenraizados e transportados para múltiplos contextos, negros e negras gestaram estruturas narrativas que transcendiam e transcendem tanto às estruturas dos estadosnação, como os limites da etnia e da particularidade nacional. A estrutura viajante do exilado, enquanto foi uma limitação, também permitiu formas agudas de experiência e narrativa, as quais escapavam aos rótulos específicos e fixos de identidade colocados pelo mundo moderno (Gilroy, 2012).

\footnotetext{
${ }^{3}$ Em definição sintética, Fábio Nogueira de Oliveira se refere à categoria de Atlântico Negro como "um mesmo mutável: as experiências diaspóricas negras são formações transculturais e internacionais das quais emergem diferentes formas de construir identidades raciais e políticas em relação à modernidade e na modernidade, a qual foi, originalmente, uma forma de pensar o Ocidente” (2011, p. 46 e 47).
} 
Na topografia da lealdade e das identidades do Atlântico Negro, que transcendem as postas pelo modelo de estado-nação, a experiência histórica foi moldada por meio do ziguezague dos movimentos dos povos negros - seja como sujeitos escravizados, seja engajados em várias lutas por liberdade -, o qual propiciou um meio próprio para reexaminar problemas de nacionalidade, posicionamento, identidade e memória histórica (Gilroy, 2012).

Como coloca Gilroy, por meio da argumentação de W. E. B. Du Bois, a vivência transatlântica possibilitou a formação de uma dupla consciência em relação ao mundo moderno, ou seja, a política cultural do Atlântico Negro como algo que é externo e, ao mesmo tempo, interno ao ocidente (2012). Assim, essa condição do exilado em um novo mundo estruturou um senso discursivo que se colocava dentro e fora da modernidade, que dela se apropriava, mas também a rejeitava. Que confrontava o legado moderno tanto para criticá-lo em suas insuficiências e impossibilidades, como para demandá-lo em suas promessas.

Mas mais do que isso: o Atlântico Negro exigiu e exige uma reestruturação e reperiodização do que se tem como modernidade diante dos impactos globais e diferenciados do colonialismo (Hall, 2013), bem como colocava e coloca em questão as leituras sobre o moderno que negam ou apagam o uso seletivo das ideologias da Era da Revoluções pelo radicalismo das revoltas dos povos escravizados e, posteriormente, pelos movimentos sociais anticoloniais e de libertação africana. Assim, em contraposição a uma separação em compartimentos estanques, a cultura política da diáspora africana aponta para o completo entrelaçamento da modernidade e do colonialismo, em que as narrativas advindas dos pontos de vista dos escravos e de seus descendentes permitem perspectivas diferenciais da história moderna, desestabilizando as noções de progresso e exigindo uma visão dinâmica do poder e da dominação nas sociedades coloniais. Portanto, a perspectiva do exilado do Atlântico Negro não só expõe o processo de exploração econômica no mundo colonial, mas também permite uma reconsideração das categorias centrais do projeto iluminista, como a coerência do sujeito, o etnocentrismo e a crença na razão (Gilroy, 2012).

Especificamente em relação à estrutura narrativa em torno dos estados-nação e da própria nacionalidade, essa posição inicial de exilado pode ter sido transfigurada para a perspectiva que as feministas negras costumam chamar de outsider-within, ou a estrangeira de dentro. Para Patricia Hill Collins, falando especificamente das mulheres negras, os saberes e práticas desenvolvidos no interior das comunidades negras possibilitou a formulação de um conhecimento oposicional aos hegemonicamente estabelecidos nas sociedades nacionais (2009). Dessa condição de marginalidade particular, emerge uma forma de compreensão da realidade que é construída fora das instituições formais, como na música, nas lideranças comunitárias e políticas, em romancistas, em doutrinadores religiosos e etc.

Assim, há a emergência de uma forma particular de apreensão da realidade que rejeita a separação moderna entre sujeito e objeto, afirmando justamente a importância da experiência como forma de estabelecer um vínculo entre o mundo vivido e a consciência (Collins, 2009). Esse local da experiência, que busca restaurar o conhecimento vivido, possibilita um outro olhar sobre as relações sociais, desenlaçando críticas às narrativas hegemônicas nacionais (Ramos, 1995). Ao "retirar o véu da moderna ideologia nacional", o ponto distintivo do Atlântico Negro fala às estruturas oriundas do poder colonial para desnudá-las como eminentemente precárias e passíveis de desconstrução. 
Permeado por experiências díspares e dinâmicas, oriundas das múltiplas formas de dominação colonial e reinvenção da África no cotidiano da diáspora, essa perspectiva do Atlântico Negro não busca essencializar o ponto de vista, pois o concebe como necessariamente heterogêneo. Valoriza-se, assim, justamente o reconhecimento das diferenças como passo necessário para o fortalecimento da teoria e da prática (Lorde, 2007).

Dentro desse contexto da importância do particular, a ideia do "escrevo o que eu quero" (Biko, 1990) é central, pois, na medida em que o conhecimento emana e se performatiza a partir do corpo, em uma espécie de corpo-política do saber, a incorporação da biografia, da experiência e do mundo privado geram efeitos disruptivos nas realidades pós-coloniais. 0 ruído criado pela fala do subalternizado é a própria transposição da sua posição de objeto para a de sujeito da história. E com este movimento, o ato discursivo desestereotipa e humaniza, complexifica e deslegitima as representações padronizadas das relações sociais estabelecidas pelas narrativas hegemônicas. O "outro" deixa de ser mero "fóssil de museu", representado a partir das tintas coloniais, para ser vida e voz ativa sobre si (Ramos, 1995).

Com acuidade e agudeza particulares, o livro “Ain't I a woman: black women and feminism", de bell hooks, é um exemplo da articulação dessas diversas questões em uma escrita historiográfica sobre os Estados Unidos e as respectivas relações de raça e gênero (2015). A partir da perspectiva das mulheres negras, que estiveram grande parte da história estadunidense no centro do poder branco, a Casa Grande, podendo perceber a formação e as contradições das estruturas de dominação e formação da verdade, mas sem nunca fazer parte delas, a escritora tece uma narrativa que nasce do privado e do particular, mas que alcança e possibilita leituras de fenômenos universais do colonialismo, como as dinâmicas e atribuições de papéis sob uma ordem machista-patriarcal e de imperialismo racial; a institucionalização do terror e da violência (os açoites, estupros, a nudez forçada, os linchamentos, a pulverização dos estereótipos); a conveniência dos discursos supostamente racionais e científicos com a subordinação racial; a estruturação da cidadania excludente nos contextos pós-coloniais, asseguradora das clivagens oriundas do sistema escravista; e a apropriação e reinvenção dos discursos e ideias de liberdade e igualdade por negros e negras no seu confronto com a ordem supremacista branca (2015).

Assim, na escrita sobre a história advinda do Atlântico Negro, faz-se uma aproximação ao passado a partir da dor, da memória, do privado, das fontes não formais, da estética (das artes) e das margens da sociedade, tendo em vista que as realidades coloniais e pós-coloniais impediram, em grande medida, a transmissão autônoma da experiência por parte de negros e negras em suas instâncias oficiais de produção de discurso (academia, mídia, poderes institucionalizados e etc.). Essa impossibilidade de acesso ao passado - ou de vê-lo como algo que já foi - acompanha a condição de exílio da política cultural negra: "o que passou" é, a todo momento, presentificado, borrando as noções bem delimitadas entre passado, presente e futuro.

Este passado que transborda no presente é resgatado tanto pela memória como pelas consequências materiais e subjetivas permanentes do colonialismo, exigindo, portanto, uma postura do historiador que leve a sério tanto os relatos do cativeiro e da experiência escrava, como as narrativas contemporâneas em relação à continuidade do genocídio humano e epistêmico dos povos negros nos contextos pós-coloniais (Carneiro, 2005; Mattos, 2007).

Não se trata portanto de apenas "colocar negros e negras como sujeitos da história" ou formular uma "história dos negros e negras", que reconduz, por outras vias, negros e negras para 
o lugar da história local ou da diferença cultural, mantendo a hierarquia dos tempos históricos a partir do padrão moderno-ocidental. Ao contrário, trata-se de realizar um movimento que, ao enxergar o entrelaçamento entre as afirmações e os apagamentos do projeto moderno com o domínio colonial a partir da condição de estranhamento inerente à diáspora africana, articule uma percepção capaz de compreender as continuidades históricas das formas coercitivas e violentas de produção e reprodução das identidades como desigualdades (Rufer, 2010).

Como na relação estabelecida por Baudelaire com o tempo parisiense expresso na superfície da cidade, a condição do estrangeiro e do estranhamento é constitutiva da política cultural e das reconstruções narrativas elaboradas por negros e negras no mundo atlântico. Ambas gozam de uma relação tensa com a temporalidade, em que a situação de precariedade e aceleração forçadas geram melancolia e temor. O passado não volta mais, a não ser na forma de ruínas e dores, e o futuro tornou-se ameaçador, o qual, na sua imprevisibilidade quebradiça, rompe com qualquer perspectiva de progresso e certeza no amanhã.

No entanto, se para Baudelaire e suas diversas figuras a situação de excêntrico e a qualidade de "circular por aí", absorvendo diversas experiências, foi um estilo de vida quase que voluntariamente escolhido diante da emergência da sociedade de massas parisiense, para os povos negros e negras, descendentes da diáspora africana e do colonialismo, a condição de exilado foi imposta, antecipando as angústias e problemas que o pensamento moderno-ocidental colocaria como próprios aos séculos XIX e, sobretudo, XX.

Se todo africano é um historiador do seu povo, como Hampaté Bâ argumentou ao falar da transmissão da experiência pela oralidade nas comunidades tradicionais africanas ainda não impactadas pelos efeitos destrutivos da modernidade-colonialidade (2010), o mesmo pode ser dito sobre os "exilados" no Atlântico Negro, ou seja, negros e negras nas sociedades póscoloniais. No entanto, são historiadores em um sentido diferente daquele primeiro, pois realizam um fazer da história que deve lidar com as condições intrínsecas de destruição da experiência, de incerteza, de precariedade e de inacessibilidade plena ao passado oriundas da colonialidade, da modernidade e do racismo.

\section{CONCLUSÃO}

O presente artigo pretendeu trazer a importância da perspectiva do exilado, do estrangeiro, do estranho ou do extraterritorial para pensar as características do ofício do historiador no regime de historicidade inaugurado pela modernidade e, agora pode ser dito também, pelo colonialismo. Através da figura instável e excêntrica de Baudelaire, trabalhada pelo gênio de Benjamin, coletamos importantes singularidades da percepção histórica nesta nova temporalidade quebradiça, ameaçadora e precária, em que a condição do exilado no seu próprio tempo emerge como perspectiva particular do contemporâneo nas suas relações com o passado, o presente e o futuro. A partir desse movimento, notamos como a situação de exílio, encarnada na dupla consciência, foi condição imposta a todos aqueles que foram alvos da escravidão e do colonialismo, bem como aos seus respectivos descendentes. Foi esse cenário de exílio que, apesar das suas limitações, forneceram um ponto de vista distintivo aos integrantes da política cultural do Atlântico Negro, os quais recusaram e deslocaram as estruturas explicativas oriundas do complexo moderno-colonial. 
Essa forma de ser, estar e perceber a contemporaneidade não só valoriza as diferenças das experiências para a produção do conhecimento e do saber histórico, mas também reivindica a mudança da geografia da razão por meio de um trabalho desconstrutivo e reconstrutivo (Alcoff, 2016). Aponta, assim, como as narrativas hegemônicas desautorizaram sistematicamente a perspectiva dos grupos subalternizados, ancorando-se em condições objetivas de dominação e exploração (Spivak, 2010).

Mas a condição do exilado não faz isso a partir de uma perspectiva de completa exterioridade, pois, ao falar ao poder, profana a ideia de verdade por ele emitida. Falando desde dentro, por meio de uma disrupção da diferença na formação estável do discurso, inaugura uma outra versão do acontecimento, da própria história. Ao mostrar, a partir de uma perspectiva particular, a continuidade como marca colonial no presente, o exilado procura gerar uma torção na linguagem da história, cancelando a autoridade do poder e a reprodução das diferenças e desigualdades a elas atreladas (Rufer, 2010).

Ao habitar e estar na situação do confronto entre dois mundos, em uma posição necessariamente deslizante, marginal, fronteiriça e estranha às histórias hegemônicas (nacionais, étnicas, científicas, econômicas e etc), o exilado as utiliza para desestabilizar essencialismos e mostrar que a continuidade está na hierarquização de sujeitos, unidades políticas e regimes históricos (Bhabha, 2013; Rufer, 2010). Estes são engendrados para totalizar a narrativa e silenciar, ocultar, diminuir ou apagar o que foi e é diferente, espontâneo e oposicional.

Nestas disputas sobre o discurso, que no fundo são disputas sobre as relações de poder, finalizo trazendo a frase de um grande professor meu que diz que "a história é uma ciência e toda ciência é uma forma de poesia". " Sendo a ciência uma elaboração poética, como toda poesia, ela é um confronto com a linguagem, um tensionamento com o léxico estabelecido. É um movimento material em volta e em face do indizível, circundando-o e o atacando. Busca tornar dizível o que não o é. Na sua aproximação do passado em mediação com um presente em constante mudança, a disrupção linguística aparece no ofício do historiador como tentativa de dar presença ao ausente, o que implica, consequentemente, na própria reorientação espacial da linguagem.

Assim como a experiência do martinicano na França trazida por Fanon em "Pele Negra, Máscaras Brancas" (2008), marcada por uma existência instável de apropriação e reelaboração de um campo semântico que não é o seu, há também na ciência, bem como na poesia, um trabalho inventivo de criação linguística, de elaboração de símbolos e recriação textual para explicar o que não era, até então, passível de explicação possível. Mas, da mesma forma que no martinicano fanoniano, a condição de existir na nova pátria e de se apropriar dos signos dominantes pode se dar através da mera reprodução de uma ordem de verdade préestabelecida, caso seja feita em reverência à instituição, ao poder. O que liberta o martinicano e, assim acredito eu, o historiador é seu compromisso ético de desnudar o poder como algo precariamente e historicamente humano a partir de uma diferença que é estranha ao seu próprio tempo, de uma diferença que é inerente à perspectiva do exilado.

\footnotetext{
${ }^{4}$ Daniel Barbosa Andrade de Faria, que não só me proporcionou boa parte das reflexões sobre Benjamin expostas ao longo do texto, como o próprio artigo foi fruto de sua matéria Teoria e Metodologia da História, ofertada pelo Programa de Pós-Graduação em História da Universidade de Brasília.
} 


\section{REFERÊNCIAS}

Agamben, G., (2009), O que é o contemporâneo? e outros ensaios, Trad. Vinícius Nicastro Nonesko, Chapecó, Brasil: Argos.

Alcoff, L. M. (2016). Uma epistemologia para a próxima revolução. Revista Sociedade e Estado, Universidade de Brasília, 31(1), 129-143.

Bâ, A. H, (2010), A tradição viva. In: J. Ki-Zerbo (Ed.), História geral da África, l: metodologia e préhistória da África (pp. 167-212). Brasília, Brasil: UNESCO.

Bhabha, H. K., (2013), O local da cultura, Trad. Myriam Ávia Eliana Lourenço de Lima Reis, Gláucia Renate Gonçalves, Belo Horizonte, Brasil: Editora UFMG.

Benjamin, W., (1989), Charles Baudeleire: um lírico no auge do capitalismo, Trad. José Martins Barbosa, Hemerson Alves Baptista. São Paulo, Brasil: Brasiliense.

(1987), Magia e técnica, arte e política: ensaios sobre literatura e história da cultura, Trad. Sergio Paulo Rouanet. São Paulo, Brasil: Brasiliense.

Bernardino-Costa, J., (2015), Saberes subalternos e decolonialidade: os sindicatos das trabalhadoras domésticas no Brasil. Brasília, Brasil: Editora Universidade de Brasília.

Biko, S., (1990), Escrevo o que eu quero, Trad. Grupo Solidário São Domingos. São Paulo, Brasil: Editora Ática.

Carneiro, S., (2005), A construção do outro como não-ser como fundamento do ser, Tese de doutorado do Programa de Pós-Graduação em Educação da Universidade de São Paulo, Brasil.

Certeau, M., (2011), História e psicanálise: entre ciência e ficção, Trad. Guilherme João de Freitas Teixeira, Belo Horizonte, Brasil: Autêntica Editora.

Collins, P. H., (2009), Black feminist thought: knowledge, consciousness, and the politics of empowerment, Nova York, Estados Unidos: Routledge.

Connel, R. (2012). A iminente revolução na teoria social. Revista Brasileira de Ciências Sociais, 27(80), 09-20.

Dubois, L. e Scott, J. (2010). Introduction. In. L. Dubois e J. Scott. Origins of the Black Atlantic. Nova York, Estados Unidos: Routledge.

Fanon, F., (2008), Pele negra, máscaras brancas, Trad. Renato da Silveira. Salvador, Brasil: EDUFBA.

Gilroy, P., (2012), O Atlântico Negro: modernidade e dupla consciência, Trad. Cid Knipel Moreira, São Paulo, Brasil: Editora 34.

Ginzburg, C., (1993), El juez y el historiador: consideraciones al margen del proceso Sofri, Trad. Alberto Clavería, Madri, Espanha: Anaya e Mario Muchnik.

, (2007), O fio e os rastros: verdadeiro, falso, fictício, Trad. Rosa Freire d'Aguiar e Eduardo Brandão, São Paulo, Brasil: Companhia das Letras.

Gumbrecht, H. U., (2015), Nosso amplo presente: o tempo e a cultura contemporânea, Trad. Ana Isabel Soares. São Paulo, Brasil: Editora Unesp.

Hall, S., (2013). Da diáspora: Identidades e mediações culturais, Organização Liv Sovik, Tradução Adelaine La Guardia Resende ... [et all], Belo Horizonte, Brasil: UFMG.

Hartog, F., (2015), Regimes de historicidade: presentismo e experiências do tempo, Belo Horizonte, Brasil: Autêntica Editora.

Hoogs, B., (2015), Ain't I a woman: black women and feminism. Nova York, Estados Unidos: Routledge.

Koselleck, R., (2014), Estratos do tempo: estudos sobre história, Trad. Markus Hediger. Rio de Janeiro, Brasil: Contraponto/PUC-Rio. 
(2006), Futuro passado: contribuição à semântica dos tempos históricos, Trad. Wilma Patrícia Maas, Carlos Almeida Pereira, Rio de Janeiro, Brasil: Contraponto/PUC-Rio.

Kracauer, S., (1995), History: the last things before the last. Completada após a morte por Paul Oskar Kristeller, Nova York, Estados Unidos: Oxford University Press.

Kristeva, J., (1994), Estrangeiros para nós mesmos, Trad. Maria Carlota Carvalho Gomes, Rio de Janeiro, Brasil: Rocco.

Lorde, A., (2007), Sister outsider. Nova York, Estados Unidos: Crossing Press.

Machado, C. E. J. (2006). Notas sobre Siegfried Kracauer, Walter Benjamin e a Paris do Segundo Império - pontos de contato. História, São Paulo, 25(02),48-63.

Mattos, H. (2007). Ciudadanía, racialización y memoria del cautiveiro en la Historia de Brasil. Trad. Francisco Ballén. In: C. M. Rosero-Labbé e L. C. Barcelo, Afro-reparaciones: Memorias de la Esclavitud y Justicia Reparativa para negros, afrocolombianos y raizales, Bogotá, Colombia: Universidad Nacional de Colombia, Facultad de Cienciais Humanas, Centro de Estudios Sociales (CES).

Mintz, S. W. e Price, R., (2003), O nascimento da cultura afro-americana: uma perspectiva antropológica. Rio de Janeiro, Brasil: Pallas/Universidade Candido Mendes.

Morrison, T. (2000). Living Memory: Meeting Toni Morrison. In: P. Gilroy. Small Acts. Londres, Inglaterra: Serpent's Tail.

Oliveira, F. N. (2011). Modernidade, política e práxis negra no pensamento de Clóvis Moura. PLURAL, Revista do Programa de Pós-Graduação em Sociologia da USP, 18(1), 45-64.

Prost, A., (2008), Doze lições sobre a história, Trad. Guilherme João de Freitas Teixeira, Belo Horizonte, Brasil: Autêntica Editora.

Queiroz, M. V. L., (2017), Constitucionalismo Brasileiro e o Atlântico Negro: a experiência constituinte de 1823 diante da Revolução Haitiana, Rio de Janeiro, Brasil: Lumen Juris.

Ramos, A. G., (1995), Introdução crítica à sociologia brasileira. Rio de Janeiro, Brasil: Editora UFRJ.

Rancière, J. (2011). O conceito de anacronismo e a verdade do historiador. In: M. Salomon (org.), História, verdade e tempo, Chapecó, Brasil: Argos.

Rufer, M. (2010). La temporalidad como política: nación, formas de pasado y perspectiva poscoloniales. Memoria y Sociedad, Universidad Javeriana, Bogotá (Colombia), 14(28), 11-31.

Said, E. W., (2005), Representações do intelectual: as Conferências de Reith de 1993, Trad. Milton Hatoum, São Paulo, Brasil: Companhia das Letras.

Spivak, G. C., (2010), Pode o subalterno falar?, Trad. Sandra Regina Goulart Almeida, Marcos Pereira Feitosa, André Pereira Feitosa, Belo Horizonte, Brasil: Editora UFMG. 